\title{
Switching from a first to a second tumour necrosis factor (TNF) alpha antagonist in patients with juvenile idiopathic arthritis H Schmeling ${ }^{* 1}$ and G Horneff ${ }^{2}$
}

Address: ${ }^{1}$ Hospital for Sick Children, Toronto, Canada and ${ }^{2}$ Asklepios Klinik, Sankt Augustin, Germany

* Corresponding author

from $15^{\text {th }}$ Paediatric Rheumatology European Society (PreS) Congress

London, UK. 14-17 September 2008

Published: 15 September 2008

Pediatric Rheumatology 2008, 6(SuppI I):P4I doi:I0.I I86/I546-0096-6-SI-P4I

This abstract is available from: http://www.ped-rheum.com/content/6/SI/P4I

(c) 2008 Schmeling and Horneff; licensee BioMed Central Ltd.

\section{Background}

Etanercept has been the only TNF antagonist licensed for treatment of resistant polyarticular juvenile idiopathic arthritis (JIA) and Adalimumab recently became the second one. Our objective was to evaluate efficacy and safety after switching from Etanercept to Adalimumab in JIA patients.

\section{Methods}

Prospective data were obtained using the database of the German Etanercept Registry. Reasons for switching to Adalimumab were recorded. Efficacy was assessed using the PedACR30/50/70 criteria. Safety assessments were based on the reporting of adverse events (AE).

\section{Results}

A total of 33 patients initially treated with Etanercept were switched to Adalimumab after a mean of 25.9 months (range 3-87 months). Reasons for discontinuation of Etanercept were inefficacy $(\mathrm{n}=23,65.8 \%)$, uveitis $(\mathrm{n}=6$, $17.1 \%)$, intolerance $(n=3,8.6 \%)$ and patients' request ( $n$ $=6,17.1 \%)$. Follow up data on Adalimumab were obtained from 12 patients for a range of 2 to 26 months (mean 10.9 months). The maximum response rate of the PedACR30/50/70 on Etanercept was 82.4\%/73.5\%/ $67.6 \%$. The last documented response rate on Etanercept showed a decrease to $47.1 \% / 35.3 \% / 29.4 \%$ (PedACR30/ 50/70). After switching to Adalimumab a maximum PedACR30/50/70 of 75\%/66.7\%/50\% compared to start of Etanercept and 33.3/33.3/25 compared to start of Adalimumab was reached. Treatment on both drugs was safe with no report of serious AE.

\section{Conclusion}

Although a number of patients have reached a good PedACR response rate on Etanercept, treatment was unsatisfied and therefore it was switched to Adalimumab. According to the PedACR only minor improvement was observed after switching to Adalimumab. 